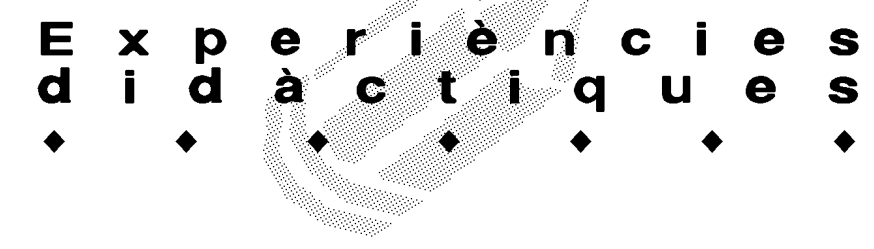

\title{
XEEPS, XEPS, PESE: PROGRAMA D'EDUCACIÓ PER A LA SALUT A L'ESCOLA
}

\author{
Montserrat Moreno Martínez. Mestra i coordinadora del PESE al CEIP Pau Delclòs. Tarragona
}

\section{Introducció}

L'època que ens toca viure no és gens fàcil i mentre vivim el present tenim una certa preocupació pel futur. És per això que la nostra escola, des del curs 2002-03, i davant unes inquietuds per la salut de la nostra comunitat educativa pertany a la XEEPS, és a dir, la Xarxa d'Escoles Europees Promotores de Salut, que té els seus orígens en un projecte europeu iniciat l'any 1995 per iniciativa tripartida de l'OMS, CE i CUE, amb l'objectiu d'assolir un estil de vida saludable per part del conjunt de la comunitat educativa.

Catalunya va participar en el projecte amb 8 escoles, coordinades des del Programa d'Educació per a la Salut a l'Escola (PESE). El final del projecte i la seva avaluació es va produir l'any 1998. Catalunya va optar per continuar el seu projecte i actualment les escoles han participat en el projecte Forum 2004 en temes de sostenibilitat, diversitat cultural i altres.

EI PESE és interdepartamental, depèn alhora dels departaments d'Ensenyament i de Sanitat de la Generalitat de Catalunya. El Departament d'Ensenyament ha impulsat la inclusió de centres docents a la XEEPS des del curs 1997-98. Després d'aquest temps es considera consolidada aquesta línia de treball, per la qual cosa calia regular, amb caràcter general, el procés d'inclusió a la xarxa.

Es van reconèixer els centres que, a partir del curs 1997-98 i successius, s'havien anat incorporant a la xarxa, alhora que se'ls manté la inclusió per al proper període de tres cursos. D'altra banda, calia seleccionar altres centres que volguessin formar part de la XEEPS durant el període del 2002-2005 i en aquesta convocatòria s'obria concurs públic per a la selecció de deu centres docents. A proposta de l'equip directiu del centre, vam decidir presentar el nostre projecte. Entre d'altres condicions, es demanava implicació i participació de l'equip docent i les famílies, i s'havia d'acreditar una experiència prèvia d'almenys tres cursos desenvolupant activitats d'educació per a la salut. El repte estava servit.

Al desembre del 2002 van sortir publicats al DOG els projectes seleccionats per a la seva inclusió a la XEEPS durant tres cursos consecutius corresponents al període 2002-2005, i el CEIP Pau Delclòs de Tarragona va ser un dels deu centres triats. Va ser el moment de posar-nos a fer realitat el nostre projecte.

\section{Inclusió de la nostra escola a la XEPS}

El projecte el va presentar la directora als pares el dia de la reunió de pares, per nivells, i al professorat mitjançant un claustre i un full informatiu, on se'n feia cinc cèntims i es donaven les directrius bàsiques. També es va repartir una còpia del projecte per cicles, per consultar en qualsevol moment.

Als pares les circulars per a la convocatòria de xerrades i tallers van ser en un principi les tradicionals, però a l'acabar el curs i per a properes comunicacions vam decidir que fossin més originals, i si fos possible realitzades pels mateixos fills, amb l'incentiu de poder veure les fotografies i vídeos dels seus fills durant la relalització dels tallers.

Al consell escolar se li va donar un full informatiu semblant al dels professors

\section{EL logotip}

Aquest logotip identifica a primera vista i en tots els àmbits tot el relacionat $\mathrm{amb}$ el nostre projecte salut.

Tota la documentació interna i externa, fulls informatius, fitxes dels alumnes o qualsevol altre material o suport gràfic i/o informàtic van identificats amb el logotip.

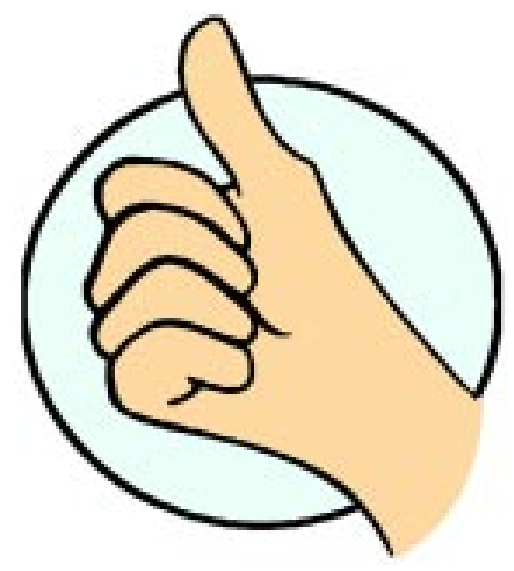

\section{L'objectiu}

EI PESE té per objectiu vetllar per la incorporació de l'educació per a la salut en tots els seus aspectes, com són: alimentació i nutrició, trastorns del comportament 


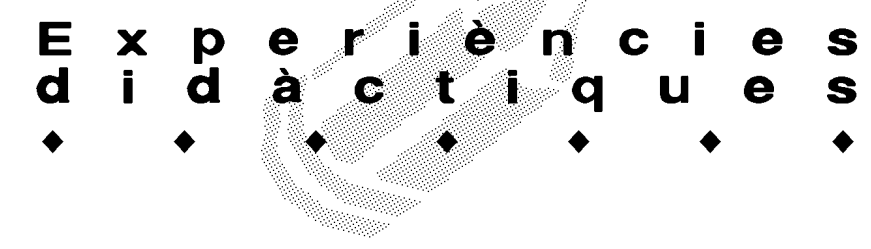

alimentari, sexualitat i afectivitat, seguretat i salut, salut mental, higiene i salut, prevenció de malalties i alimentació als menjadors escolars.

EI PESE vol ser un instrument eficaç per potenciar la incorporació dels continguts i de les estratègies positives de salut en el marc de l'escola.

L'educació per a la salut és un procés de formació de l'individu amb l'objectiu que aquest adquireixi els coneixements, les actituds $i$ els hàbits bàsics per a la defensa i la promoció de la salut individual i col-lectiva.

Les escoles promotores de salut tenim per finalitat el foment i l'adopció d'estils de vida sans en un ambient favorable a la salut, i per al seu compliment, ens comprometem a promoure un entorn físic i psicosocial saludable, segons les possibilitats.

Per tal d'assolir la citada finalitat s'ofereixen, tant a l'alumnat com al personal docent i no docent, diverses opcions realistes i, a la vegada, atractives, en matèria de salut.

Com a centre seleccionat ens comprometem a dur a terme el projecte i a participar en les activitats de formació i coordinació del PESE, de la Direcció General d'Ordenació i Innovació Educativa.

\section{Recursos}

El Departament d'Ensenyament afavoreix el desplegament d'accions de prevenció i promoció de la salut en els centres educatius, mitjançant la tramesa de materials didàctics i la prestació d'assessorament als centres de Catalunya que formen part de la XEEPS.

Rebem assessorament, per part del PESE, fins a un màxim de $20 \mathrm{~h}$ per curs escolar, que repartim entre actuacions dirigides als alumnes, al professorat i a les famílies i personal no docent. També rebem material i propostes didàctiques.

Les despeses econòmiques (compra d'aliments, material fungible, etc. ) van a càrrec del centre, encara que aquest curs estem buscant ajuts, aportacions 0 colaboracions de diferents institucions, empreses i entitats.

\section{La coordinació}

Existeix la figura del coordinador del projecte, que té com a funcions:

a) Coordinar les activitats de promoció de la salut, tot dinamitzant l'equip docent per al desenvolupament del projecte.

b) Impulsar, seguir i avaluar el projecte.

c) Assistir a les reunions convocades pel programa.

d) Elaborar la memòria anual.

\section{EI XEPSCAT}

Per a facilitart l'intercanvi i la comunicació entre els membres de la Xarxa d'Escoles Promotores de Salut -on la direcció del PESE actua com un membre més entre els centres que formem part del programatreballem en xarxa mitançant les llistes de distribució, que ens permet tenir un debat de grup o compartir informació per part de qualsevol membre de la llista (no de manera unidireccional, com es fa la web), per mitjà del correu electrònic. Cal subscriure's i es rep el correu del grup a la bústia particular (personal o de centre). Aquesta acció de donar-se d'alta a la llista és l'única acció específica que requereix una llista, la resta del seu funcionament és exclusivament l'ús del correu electrònic.

La llista XEPSCAT es pot fer servir per a informar els companys sobre novetats, materials, convocatòries, propostes d'activitats, informacions concretes, que poden

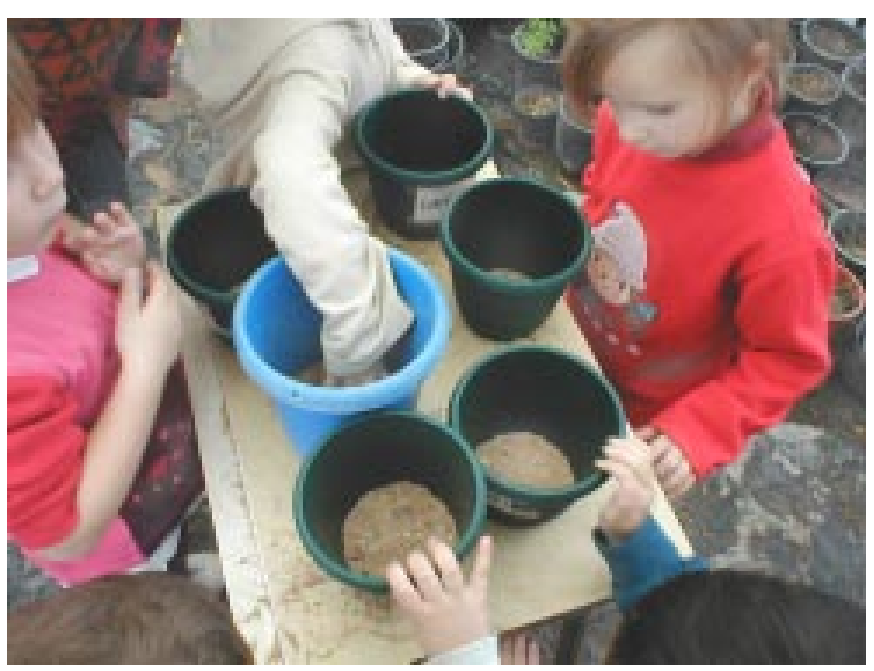

passar a la pàgina web. També es pot exposar opinions, fer consultes, valorar activitats o materials, demanar informació al col-lectiu sobre temes concrets, etc.

\section{Metodologia}

En relació amb el professorat, som conscients de les seves múltiples tasques i que el que falta és temps. Potenciem una comunicació eficaç entre els membres oferint una informació ràpida, clara i operativa, mitjançant una reunió informativa a principi de curs sobre el pla d'actuació i facilitant-los una graella de la programació dels nivells, horaris i continguts de les actuacions que es faran al llarg del curs. Per a temes concrets reunim els coordinadors de cicle i es dóna la informació, les còpies dels acords, o es donen les graelles corresponents a la presa de decisions, conclusions, avaluació, buidatges, etc perquè ho transmetin al seu cicle, establint una relació de feedback. A final de curs es tornen a reunir els cicles per recollir les valoracions, observacions i els temes proposats per al curs següent, i el claustre per informar dels resultats i comentar. 


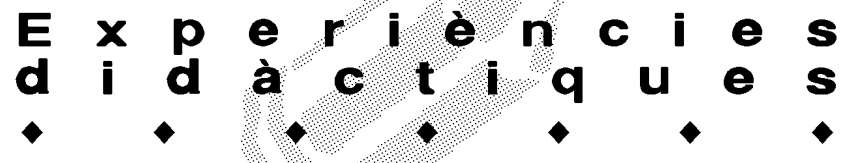

En relació amb l'alumne, la metodologia s'adequa al cicle i nivell, tenint sempre present que sigui motivadora, amb un aprenentatge significatiu i constructiu. Es vetlla per una metodologia activa i participativa i perquè s'impliquin en el procés d'ensenyament-aprenentatge. Les actuacions suposaran un interrogant a més d'un repte, $\mathrm{i}$ els mateixos alumnes provaran de trobar les respostes a les diferents qüestions plantejades, fomentant el criteri propi, tot establint diàlegs i debats, afavorint l'expressió oral comunicativa.També es proposen certs actes que impliquen tota la comunitat. Són actes oberts a tota la ciutat, que poden ser al carrer o fora del recinte de l'escola, en col-laboració amb diverses entitats i altres centres educatius.

En relació amb pares i mares, sempre que és possible afavorim que participin el màxim de sentits possibles. Perquè siguin operatives han de ser d'un tema prou interessant, que els afecti de prop i que puguin parlar i exposar las seves vivències. En un tema com la nutrició el sentit del gust és imprescindible, i cada taller i/o xerrada es complementa o finalitza amb un tast. Això fa que no ho trobin pesat, ja que en certa manera estan cansats de rebre convocatòries de reunions de tots tipus i per part de diferents entitats al llarg del curs, i cal que seleccionin i se sentin motivats per a les que farem sobre el tema de salut. Així, i mai millor dit, marxen amb un bon gust de boca! D'aquestes reunions recollirem les propostes dels temes que més els preocupin per al següent curs.

També hem decidit fer una prova per trobar l'horari més adient per fer les xerrades: de $15 \mathrm{~h}$ a $17 \mathrm{~h}$ i de $19 \mathrm{~h}$ a $21 \mathrm{~h}$ i avaluant els resultats decidim fer totes les següents de 3 a 5 de la tarda, i així es queden quan deixen els seus fills/es i a l'acabar els recullen. Cal dir que es va apreciar un canvi d'hàbits en l'esmorzar dels fills dels pares que hi havien assistit: més entrepans, més fruita i menys pastisseria industrial.

\section{Les activitats}

Activitats anteriors

A l'escola, a banda dels continguts curriculars i com a eix transversal, hi ha hagut una llarga intervenció educativa adreçada a la promoció d'hàbits saludables al llarg dels darrers anys, distingint dos grans grups, les concretes i les continuades. Destaquen d'entre les primeres els esmorzars cardiosaludables; propostes didàctiques sobre els transtorns de l'alimentació; l'aventura de la vida; xerrades-taller sobre salut i higiene bucodental; tallers de primers auxilis; les campanyes de la poma; escola de pares, sobre psicomotricitat i alimentació; sortides pedagògiques a granges-escola i a horts ecològics; el programa APQUA 10-12; participació en el programa de prevenció i control de la càries dental; la prevenció de les drogodependències i altres conductes de risc a partir del material "Els meus amics, el meu jardí"; taller sobre la campanya divulgativa del SIDA.

Les accions continuades són les que el professorat va portant a terme al llarg de tot el curs, contemplades com a contingut curricular específic d'unes árees determinades que formen part del nostre PEC i PCC.

Cada activitat requereix un espai adient $\mathrm{i}$ alguns s'han efectuat fora de l'àmbit i horari escolar.

Les activitats del curs 2002-03

El passat curs, el primer de la nostra pertinença a la xarxa, vam iniciar aquest programa portant a terme determinades activitats adreçades als alumnes, al professorat i als pares i mares. El tema monogràfic va ser l'alimentació ja que ens preocupava a tots, es veia a les aules i per la realitat sòcio-cultural que vivíem vam pensar de fer-ho extensiu a tots els cicles ja que així ens permetía lligar, motivar i uniformar les activitats, informacions $i$ actuacions internes $i$ externes vers al mateix tema i aconseguir una unitat a nivell d'escola, d'ambientació, i de comentaris internivells. Per ser el primer any era millor unificar. Per als més grans es va complementar amb els primers auxilis. Es va fer càrrec d'aquests tallers personal especialitzat enviat pel Departament d'Ensenyament i comptant amb la continuïtat a l'aula per part del professorat.

Les activitats són les següents:

Parvulari: Juguem a menjar bé: (els colors, els gustos, les textures, el tacte...

Cicle inicial: Els aliments i el grup a què pertanyen: els cereals, la fruita; com complementar un menú i taller de pastisseria.

3r nivell de cicle mitjà: La seguretat amb el foc; el triangle del foc, les posicions de seguretat; les cremades solars.

4t nivell de cicle mitjà:Actuació davant petites ferides i traumatismes, els diferents tipus de ferida, els materials adients, cops i fractures obertes i tancades, actuacions corresponents i sessió pràctica.

Cicle superior: La conservació, qualitat i processament dels aliments: la millor elecció a l'hora de la compra. Com guardar cada aliment. La degustació dels aliments comprats i comparació de qualitats.

Professorat: La salut laboral: l'estrès, el bourt-nout i el mobbing.

Pares/mares: Un berenar d'aniversari saludable. Què tenim dins la nevera? Sabem el que mengem? Els ingredients i els additius. Degustació.

A banda d'aquests tallers, de les moltes ofertes que ens arriben a l'escola vam triar: El peix blau, per aproparse a la cultura del peix; els esmorzars cardiosaludables; 


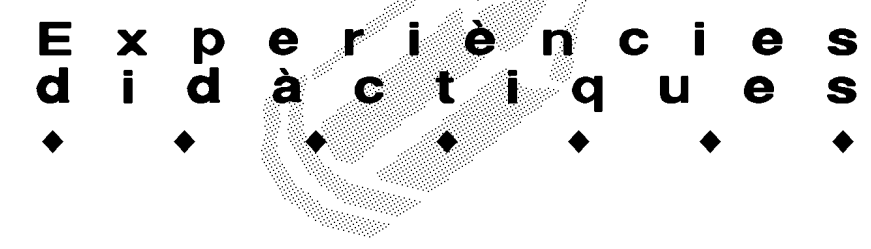

visites a diverses granges-escola per treballar l'origen dels aliments i la seva transformació; treball d'investigació sobre el moviment dels ulls; la gastronomia típica del Brasil; l'aventura de la vida; el programa escolar Colgate; el fluor, l'actimel, la poma.

Les activitats dels curs 2003-04

Enguany, després de les valoracions fetes i escoltant els suggeriments dels professors, de l'alumnat i dels pares i mares, el tema principal és la salut física, però dintre de la seva amplitud ens fixarem en els aspectes següents:

Parvulari i cicle inicial de primària: La nutrició. Substituïm les llaminadures pels fruits secs?

Cicles mitjà i superior: El sedentarisme. L'oci i el temps lliure.

Professorat: La relaxació.

Pares, mares i PND: Com fomentar l'adquisició d'hàbits en els nostres fills. Les rebequeries.

Cal dir que hem engegat el llibre del per què per

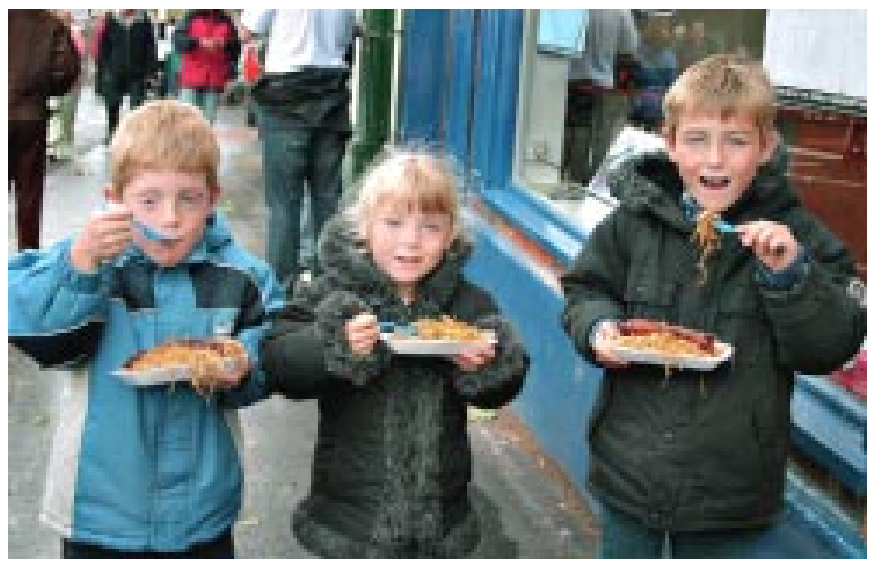

donar resposta a fets que semblen tan normals i quotidians per la seva freqüència d'actuació o d'ús, i que precisament per aquesta "normalitat" no ens parem a pensar en el seu origen, la causa o la seva raó de ser. Davant el passotisme i desinterès actual entre el nostre jovent, volem despertar la curiositat i evitar l'empassament dels agents externs o interns que poden afectar negativament la seva salut, realitzant un recull de les preguntes i respostes treballades per nivells, fent la recopilació per cicles i editant-la en suport paper i informàtic i deixar-la a les aules i a la biblioteca de l'escola com a llibre de consulta.

Pel que fa a la metodologia seguida, es té en compte que les preguntes seran realitzades pels alumnes en qualsevol o en el mateix moment que sorgeixi el fet, bé intuïdes o provocades o canalitzades pel professor.

La situació idònia per respondre la pregunta plantejada per l'alumne seria en el mateix moment en què sorgeix, però si en aquest moment ocasional que pugui sorgir el dubte sobre una qüestió específica de salut no fos l'adient per a treballar la resposta, es pot proposar la bústia o la capsa dels dubtes on el nen/a pot escriure la pregunta i posar-la dintre. Es pot acordar un dia o hora setmanal per donar les respostes.

A l'hora de trobar la resposta s'emprarà: l'experimentació i la reproducció del problema en models externs; la deducció; la conversa, el debat; el contrast d'opinions; el contrast d'experiències dels mateixos alumnes sobre aquest fet; es pot buscar la resposta en el professorat, en un consultor tant en suport de paper, informàtic o multimèdia, en un expert, o qualsevol altre mitjà que pugui ser adient, en funció de la situació i de l'edat de l'alumne.

La complexitat de les respostes canviarà, evidentment, amb el grau de maduresa dels infants, de manera que una mateixa pregunta pot tenir diverses respostes. Per exemple: davant la pregunta: "Per què t'ha sortit un blau?" després d'haver-se donat un cop al pati, un nen/a de $P-5$, la resposta que obtindrem serà més senzilla 0 més imaginativa que l'obtinguda per un nen/a de cicle superior. En aquest cas, la resposta inclourà aspectes molt més exactes i vocabulari més acurat, a més d'una resposta verbal de caire més científic.

Cal encoratjar els alumnes perquè vulguin conèixer $i$ saber més del seu cos i de la seva salut física, mental i social, i que ells intentin deduir la resposta.

També hem actualitzat el contingut de les farmacioles i s'ha posat en $\mathrm{lloc}$ ben visible un llistat amb el seu contingut i un manual bàsic de primers auxilis.

Finalment, s'ha creat la bústia dels pares per proposar receptes agradables i saludables davant de tant de menjar ràpid, precuinats i cuinats. Aquesta activitat s'ha creat recollint la proposta de les infermeres i amb l'aprovació dels pares que van assistir a les xerrades sobre nutrició, organitzades pel PESE davant del problema generalitzat dels nens i nenes que no mengen o que sempre mengen el mateix tipus d'aliment o que els costa o es neguen a ingerir aliments com verdures, llegums, fruita, fruits secs... Es va decidir elaborar un receptari amb idees, suggeriments, trucs, estratègies, enganyifes, presentacions agradables, etc. atenent sempre el perfil dels nostres comensals.

Seguirem realitzant les activitas que ens proposin les diferents entitats i organitzacions, com els esmorzars cardiosaludables, el fluor, etc.

\section{L'avaluació dels resultats}

L'avaluació també s'ha fet sobre el procés, els recursos humans i materials.

A l'acabar cada activitat sempre es pregunta, per 


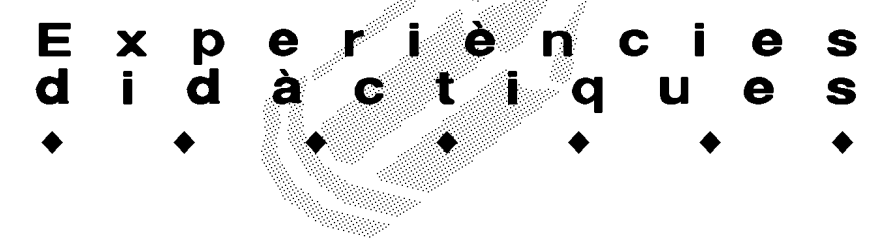

separat, l'opinió sobre la seva realització als mestres, alumnes, pares i formadors. Un cop recopilada es passa a l'equip directiu per fer, juntament amb el coordinador del projecte, la seva valoració.

Perquè en quedi constància, es passa a cada professor una graella de valoració i observacions (vegeu la figura 1).

Pel que fa a la temporització, de l'avaluació del passat curs hem pres unes decisions per millorar les intervencions d'aquest curs, ja que l'any passat, al ser el primer any, vam haver de seguir uns passos d'informació que aquest any sols ha calgut recordar; i de posada en marxa, que el curs passat es va endarrerir ja que van tenir lloc altres activitats culturals, festives i puntuals del calendari escolar amb les corresponents precipitacions per complir el programa. Enguany estem respectant i complint la temporització prevista i afiançant els objectius proposats.

Sobre les activitats, hen valorat aprofitar més l'hora dels tallers, no impartint tants continguts i eliminant la sensació de pressa i acabar cada sessió relaxadament i amb la participació de tots.

Respecte a l'ambientació escolar, també es va valorar -i ara la posarem en marxa- la idea de dedicar permanentment un espai visible al vestíbul del centre, fàcilment identificable pel nostre logotip i decorat segons l'ocasió, on s'exposaran les fotografies de les activitats relacionades amb la salut, la programació de les activitats, una còpia del projecte inicial, novetats, notícies, la bústia de les receptes saludables que unes famílies van proposar per suggerir "fórmules màgiques" per fer més agradables els plats dels fills poc menjadors, etc., i serà un espai obert a qui hi vulgui participar.

\section{Conclusió}

Recordem que la salut és un estat de benestar complet físic, mental i social, i no simplement l'absència de malaltia.

La salut física és el benestar del cos humà, la nostra alimentació, l'ergonomia, la prevenció d'accidents i riscos, les addiccions, la higiene. La salut mental és el benestar i equilibri emocional d'un mateix i de l'entorn immediat, i la salut social és entesa com la relació equilibrada de l'individu amb la societat: la relació de l'infant amb la família, amb l'escola i amb els diferents grups de la societat.

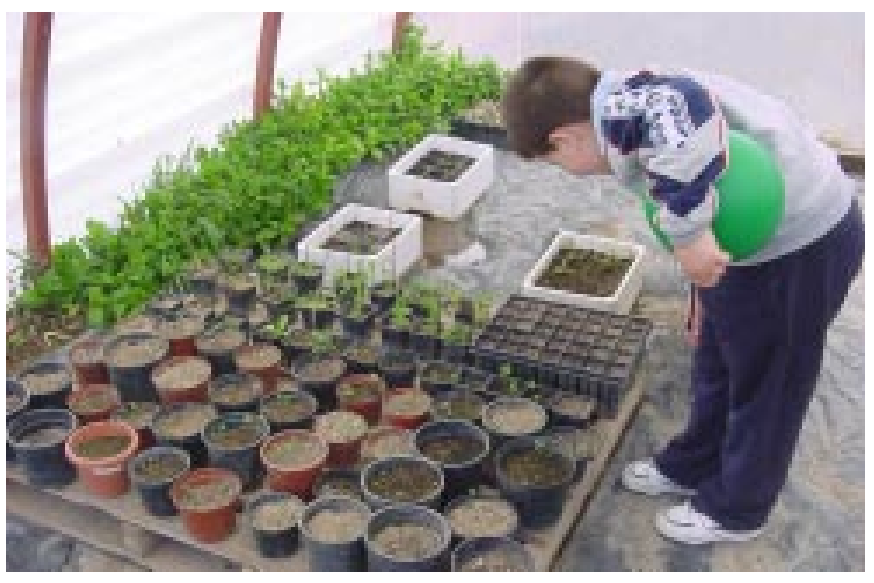

Som conscients que hem tingut errors i que d'ells aprendrem i rectificarem accions i procediments. Cada curs esperem superar els resultats i el grau de satisfacció per part de tota la comunitat educativa. També som conscients que nosaltres, com a educadors, implicats en un complex però important procés, ens hem d'anar adaptant a les diferents situacions de la nostra realitat social, cultural, biològica i psicològica que afecta i implica l'escola com a institució educadora, formadora i informadora.

"Amb la realització d'aquest projecte volem aconseguir l'adquisició d'hàbits que millorin i afavoreixin un ambient saludable des d'un punt de vista físic i psicosocial". Així començava el nostre projecte inicial i amb aquest desig i amb la il.lusió de renovar-lo cada tres anys desitgem molta salut als nostres lectors.

PROFESSOR

NIVELL/CICLE: Infantil

CURS...2002-03

\begin{tabular}{|l|l|l|l|l|}
\hline \multicolumn{1}{|c|}{ RISC } & \multicolumn{1}{|c|}{ DÈFICIT } & HÀBIT NOCIU & MANCANÇA & ALTRES \\
\hline Càries & Poc consum de fruites & $\begin{array}{l}\text { Excessiu consum de } \\
\text { sucres }\end{array}$ & \\
Sobrepès & $\begin{array}{l}\text { Poc consum } \\
\text { d'entrepans }\end{array}$ & $\begin{array}{l}\text { Consum de } \\
\text { pastisseria industrial }\end{array}$ & & \\
\hline
\end{tabular}

Figura 1. Dèficts detectats al cicle infantil. Full d'anotació de deteccions a l'aula. 